\title{
O CONSUMO ESTÉTICO-SIMBÓLICO DO SOFÁ
}

Lima, Marco Antonio Magalhães. Dr

PUC-Rio

mlimapuc@gmail.com

Resumo: Este artigo é parte do trabalho encerrado em março de 2015 que procurou verificar o consumo do sofá da sala por agentes posicionados entre as camadas popular e média baixa no espaço social carioca sob a ótica da dominação simbólica proposta por Bourdieu (1930-2002). Nesse cenário entendemos que simbolicamente esse consumo poderia ser reflexo da expressão individual desses sujeitos ou fruto de um processo coercitivo de inculcação gerado pelas instâncias de legitimação e consagração que atuam no campo de design. Para essa verificação, além da teoria de Pierre Bourdieu, lançamos mão de uma investigação sobre a produção e uso social, no ocidente, dos assentos próximos ao que hoje entendemos ser um sofá, bem como procuramos averiguar como se deu a formação do que chamamos de sala da casa no Brasil. Juntamente a esse aporte teórico realizamos uma pequena pesquisa de campo, de caráter qualitativo, em um primeiro momento com indústrias de sofá, para conhecer como esse produto é elaborado, e, posteriormente, com consumidores, para entender como se dava sua decisão de escolha do sofá. É sobre essa última que tentaremos relatar, de forma sintética, algumas considerações importantes.

Palavras-chave: consumo simbólico, violência simbólica, sofá.

Abstract: This article is part of the work ended in March 2015 that sought to verify the living room sofa consumption by agents positioned between the popular layers and lower middle layers in the Carioca social space from the perspective of symbolic domination proposed by Bourdieu (19302002). In this scenario, we understand that symbolically this consumption could be a reflection of the individual expression of these subjects or the result of a coercive process of inculcation generated by instances of legitimation and consecration operating in the design field. For this check, as well as Pierre Bourdieu's theory, we used a research on the production and social use, in the West, the seats next to what we now understand to be a sofa and try to find out how was the formation of what we call room house in Brazil. Along with this theoretical framework, we conducted a small qualitative field research, in a first moment with sofa industries, to know how this product is prepared, and later with consumers to understand how your decision to choose the couch was. It is this last that try to report, in summary form, some important considerations. 
Keywords: symbolic consumption, symbolic violence, sofa

\section{INTRODUÇÃO}

A pesquisa de campo com os consumidores de sofás ocorreu ao longo do segundo semestre de 2013. Considerando a forte subjetividade envolvida nas questões estético-simbólicas sempre estivemos inclinados a utilizar uma pesquisa empírica qualitativa de base exploratória. Entendemos que a mesma seria intenso na prospecção de visões de mundo e valores e, dada a complexidade desse tipo de abordagem, o número de entrevistados seria, evidentemente, reduzido, e de acordo com Marconi e Lakatus (1991: 85) "sem o emprego de técnicas probabilísticas de amostragem".

Para tal, em nossa coleta de dados, utilizamos a técnica de entrevista semiestruturada, lançando mão de um conjunto de questões por meio das quais procuramos descobrir como se dava o processo de escolha do sofá, empregando uma sequência que intencionou, primeiro, uma efetiva aproximação com o entrevistado, para deixá-lo a vontade durante a conversa e, segundo, entender seu modo de vida, a sua casa, seus hábitos, sem incorrer no uso de questões que pudessem suscitar uma sensação de invasão de privacidade por nossa parte (BEAUD e WEBER, 1997: 134).

Para encontrar possíveis candidatos para o intento estabelecemos alguns critérios e contamos com a ajuda de alguns colaboradores. O primeiro critério para escolha era que o entrevistado teria de ter adquirido um sofá no período de até um ano. O segundo envolveu a renda familiar média mensal, que, de acordo com o IBGE (2010), compreendia a faixa entre 5 a 10 salários mínimos. O terceiro consistiu no nível de instrução dos entrevistados, limitados ao Ensino Médio completo, seguido do nível de instrução dos pais, que estava restringido ao Ensino Básico (compreendendo o período do nascimento até a maioridade do agente, que entendemos ser o período máximo para completar a formação do seu habitus primário). A decisão de empregarmos como critério o capital cultural se justifica pelo fato de que estávamos tentando definir um conjunto de valores assimilados por esse grupo social e não definir essa "classe" por critérios puramente econômicos. Com a combinação do montante de capital cultural (incorporado e institucionalizado) e capital econômico, entendemos que poderíamos contar com agentes que, mesmo com suas diferenças inequívocas, guardariam posições aproximadas no espaço social conforme Bourdieu (2008).

Muito embora não tivéssemos a intenção de orientar a seleção da amostra pelo gênero, foi inevitável que a quase totalidade dos entrevistados fosse do sexo feminino. Na verdade nossa escolha estava limitada a um indivíduo com idade acima dos 18 anos (maioridade), economicamente ativo ou do lar, com ou sem filhos, residente no município do Rio de Janeiro. Alguns contatos inclusive foram feitos com homens que preferiam deixar a entrevista a cargo de suas esposas. De certa forma, pesquisas demonstram a evolução econômica do público feminino, como as realizadas pelo IBGE até 2012, que apontam que houve um crescimento significativo de mulheres como chefes de família, de 28\% em 2002 para 38\% em 2012. Nesse mesmo cenário, pesquisas realizadas pelo Data Popular demonstram que as mulheres da classe $\mathrm{C}$ 
detêm um nível de instrução maior que o dos homens, chefiam mais as famílias do que aquela das camadas superiores contribuindo de forma mais significativa para a renda familiar, além de exercerem o controle do orçamento doméstico e dos tipos de gastos.

Vale lembrar que desde meados do século XIX a escolha da decoração doméstica e da mobília na Inglaterra tornou-se responsabilidade da mulher, e a casa refletia sua personalidade (FORTY, 2007: 144). Considerando a forte influência britânica a que fomos submetidos no mesmo período, conforme nos assevera FREYRE (1977: 19), não seria estranho que esse comportamento também tenha sido absorvido por aqui. Também, não podemos deixar de ressaltar que desde o século XVII a casa burguesa da sociedade holandesa tinha se tornado um espaço da mulher, sendo ela a grande responsável pela evolução dos interiores domésticos que culminou ao complexo conceito de domesticidade que está relacionado "à família, à intimidade, à devoção ao lar assim como como uma sensação da casa como incorporadora [...] desses sentimentos" (RYBCZYNSKI, 1986: 82). Assim, não poderíamos deixar de reconhecer a importância da figura feminina no ambiente familiar contemporâneo, mas não vimos problema em inquirir agentes do sexo masculino em nossa pesquisa.

As questões elaboradas para as entrevistas foram divididas em quatro blocos, ordenados conforme descrito a seguir. Cabe ressaltar que a ordenação citada não foi usada de forma rígida, mas adaptada conforme ao andamento da entrevista.

O primeiro, bloco inicial, correspondeu às questões de abertura para as quais o entrevistado deveria fazer uma descrição do dia a dia de trabalho, bem como dos seus momentos de lazer, aí incluída a confirmação da existência ou não do hábito de assistir à televisão (frequência, canal, tipo de programa). Nessa parte inicial a descrição do cotidiano dos partícipes foi fundamental para a pesquisa, pois "o que eles pensam de tal ou qual coisa - suas opiniões - só tem valor e sentido a partir de suas práticas" (BEAUD \& WEBER, 1997: 144). Estávamos interessados em eventualmente identificar quais eram os valores da cultura visual dos entrevistados através dessa singela prática do brasileiro que reside na cidade e usufrui de objetos típicos da sociedade industrial depois da eletrificação dos lares, sentar-se, geralmente em um sofá, e assistir à televisão com sua família. Se o sofá do "seu gosto" seria aquele que ele viu em imagens que transitam pela TV. Pois, como sabemos, o que se vê não é apenas aquilo que se vê, não podemos naturalizar o olhar, mas um conjunto de imagens intencionalmente veiculadas, que legitimam e são legitimadas com vistas à formação de uma cultura visual, ou uma ação de reprodução dessa cultura por intermédio de um processo de violência simbólica, por parte das emissoras de TV. Nessa lógica, as novelas merecem destaque, pois o formato em que são estruturadas "potencializa a vocação da televisão para transmitir uma sensação de que os expectadores estão conectados com o mundo ao seu redor, e acena a possibilidade concreta da inclusão por meio do consumo" (HAMBURGUER, 1998: 467). Inclusive, por sua periodicidade diária e o desencadear relativamente lento, a novela propicia um profundo envolvimento dos telespectadores, que se dispõe a acompanhá-la, viabilizando por parte dos produtores um enorme campo para divulgação de produtos, considerando que o "olhar dos telespectadores está treinado para observar a marca do fogão, o tipo de salada, a distribuição de funções entre marido e mulher. Telespectadores de classes 
sociais variadas demonstram o domínio de detalhes da decoração das casas de novela" (HAMBURGUER, 1998: 483).

O segundo bloco envolveu o participante na descrição de sua própria casa, ele deveria apontar o cômodo de sua preferência e explicar a razão para tal. Por fim ele deveria fazer uma descrição de sua sala. A intenção era de fazer uma aproximação gradativa ao assunto sofá e ao mesmo tempo entender como o entrevistado interage, entende e preenche o espaço de sua casa.

O terceiro bloco compreendeu questões específicas e mais próximas ao objetivo do trabalho. Nele foi solicitado aos entrevistados que descrevessem o modelo de sofá adquirido (desenho, revestimento, cor etc.) e como se deu a decisão ou escolha de compra. Também foi perguntado se a opção do modelo do sofá foi pessoal ou compartilhada, o estabelecimento (loja) onde comprou, o valor e a forma de pagamento. Foi pedido ainda ao partícipe uma previsão do tempo de vida do sofá novo e se, quando ficasse velho, ele pensaria em forrar ou compraria um novo. Encerrando essa parte, questionamos os participantes a dizer se comprariam um sofá pela internet. Nesse bloco, além da intenção óbvia de saber como o sofá foi escolhido e comprado, queríamos saber até onde esses consumidores tem suas ações, nesse intento, influenciadas direta ou indiretamente por terceiros (vendedores, revistas, especialistas etc.). Vale lembrar que a interação das informações dos três blocos pretendiam identificar e entender a relação entre as práticas e as propriedades dos agentes (BOURDIEU, 1984: 84), para que fosse possível identificar, ainda que de forma difusa, o gosto dos agentes por nós abordados para entrevistas.

O quarto bloco envolveu questões mais pessoais do entrevistado, tais como: sua naturalidade, seu nível de instrução e dos seus pais, atividade do cônjuge (se houvesse), nível de renda familiar. Conforme citado acima essas questões foram propositalmente colocadas no final para que não houvesse qualquer tipo de constrangimento, mas, se ocorresse, a entrevista estaria próxima do fim. ${ }^{1} \mathrm{~A}$ intenção nessa parte foi a de conferir a formação do habitus (primário e secundário) desses consumidores e seu posicionamento no espaço social carioca.

Por fim, é importante dizer que embora nossa pretensão fosse que as entrevistas ocorressem na casa dos pesquisados, não apenas pela possibilidade óbvia de visualização do espaço real da sala, mas pela franca possibilidade em deixá-los mais relaxados e à vontade, o que contribuiria para qualidade das respostas (BEAUD E WEBER, 1997: 132), isso, infelizmente, na maior parte das vezes, não ocorreu em função de recusas sistemáticas que se justificavam, geralmente, pela bagunça em que a casa se encontrava ou por obras de melhorias ainda não realizadas. Por outro lado, desconfiamos que a recusa poderia ser fruto do desconforto que a visita poderia trazer ao ambiente familiar após um dia de trabalho ou mesmo na paz de um merecido fim de semana. Sendo assim, tivemos de aceitar a realização de grande parte das interlocuções nas proximidades do local de trabalho do entrevistado, aproveitando seu

\footnotetext{
${ }^{1}$ Como foi previsto, algumas entrevistas tiveram de ser descartadas em virtude dos partícipes apresentarem perfis discrepantes com relação ao volume de capital cultural que procurávamos.
} 
horário de almoço ou no fim do expediente, o que demandou um grande esforço para mantê-los concentrados e tornar a conversa frutífera.

\section{RESUMO DA ANÁLISE DAS ENTREVISTAS}

$\mathrm{Na}$ análise das entrevistas procuramos interpretar as manifestações dos agentes no papel de consumidores do sofá. Aqui nos preocupamos em apresentar um resumo dos aspectos mais significativos tendo em vista o objetivo do trabalho e as limitações impostas à extensão do documento.

Julgamos que todo o esforço por nós dedicado não é garantia de que nossa pesquisa de campo seja um retrato fiel da situação da instância de recepção dos sofás, mas certamente ela traduz parte daquilo que o referido público pensa em relação ao nosso objeto de trabalho, enfim, é uma visão aproximada. Julgamos também que talvez o aspecto mais importante é que não estávamos preocupados com a "linguagem" ou a "fala", mas com a interpretação do universo simbólico, em que o sofá tem sua existência, conforme defende Pierre Bourdieu.

Em muitos pontos dessa análise fomos obrigados a relativizar usando termos como: "a maioria", "mais da metade", "grande parte", o que sugere uma tentativa de quantificação, que evidentemente não caberia nesse universo tão pequeno, próprio de uma pesquisa desse tipo.

Podemos afirmar que, a maioria dos entrevistados é natural do Rio de Janeiro, do sexo feminino, trabalha fora, é casada e tem filhos, sendo que a metade reside em apartamentos e outra metade em casas, pelas quais, a maior parte, não pagava aluguel. Desses entrevistados, apenas um tinha acabado de comprar o imóvel, o restante era proprietário como único herdeiro ou ocupava o imóvel por consideração de familiares com os quais dividiam o direito ao patrimônio, ao que tudo indica, por não contar com vencimentos que permitissem arcar com essa despesa. Claro está que, com base na remuneração familiar declarada pela maioria, seria praticamente impossível a esses agentes a aquisição (ou mesmo o aluguel) de grande parte dos imóveis mencionados, tanto pela localização quanto pelas características declaradas.

Nos fins de semana os entrevistados com filhos pequenos costumam ajustar suas saídas aos locais com atividades infantis ou em locais e horários em que as crianças possam se distrair, muito embora já tenham tido, muitas oportunidades de diversão junto a seus cônjuges, como agora ocorre com nossa mais nova entrevistada, que, por ser mais jovem e sem filhos, foi a única que ainda goza do privilégio de poder aproveitar os fins de semana com mais liberdade. Já os dois entrevistados sem relacionamentos afetivos, são mais caseiros e dispensam atividades externas por não gostarem de "badalações" e locais com muita concentração de pessoas.

Verificamos que o hábito de receber visitas em casa parece não ser cultivado pela maioria. Aqui, não estávamos interessados nas visitas normalmente chamadas de "pessoas de casa" (avós, pais e irmãos), que por serem muito próximos dispensam a famosa "cerimônia" no ato de receber. Mas sim os de fora, que por mais que se tenha amizade, a nosso ver, demandam algum tipo de atenção por parte do dono da casa. Para justificar nossa impressão, poderíamos recorrer a declaração de uma participe de 
origem paulista, que afirmou ter notado não ser um hábito do carioca receber pessoas em sua casa, na opinião dela, por conta do calor que levaria as pessoas a se encontrar na rua. Muito embora sua teoria seja interessante ou válida do ponto de vista lógico, achamos por bem citá-la, mas não acatá-la de forma definitiva por não termos encontrado ainda dados que a comprovem. Nossa intenção nessa passagem era identificar a importância do sofá na recepção de convidados, e, ainda que a maioria não tenha se manifestado positivamente nesse sentido, demonstraram preocupação com a aparência de seu mobiliário, tendo servido inclusive como desculpa para muitos não nos receber em suas casas por falta de condições em que o sofá se encontrava.

Associado ao lazer, observamos com relação à televisão que a maior parte das pessoas assiste com certa constância, geralmente em momentos mais recatados, próximo da hora de dormir. Nesse quadro, temos os que costumam assistir sozinhos, mas de forma intensa e apaixonada, e os que assistem à TV com toda família, tendo sido declarado por uma delas que o uso da televisão vai além do lazer, como o hábito que cultivou de assistir com frequência aos jornais: "Para eles [seus filhos] poderem fazer parte daquela realidade bem dura. Não posso excluir eles dessa realidade. Sempre divido isso com eles". Na verdade, ela tem consciência de que, por vezes, os jornais veiculam notícias "pesadas" que ela procura "aliviar", com sessões de desenhos animados.

Vale ressaltar que mesmo considerando que metade dos entrevistados acompanham o andamento de novelas com certa periodicidade, entendemos que com o advento da TV por assinatura, com programas que vão da culinária ao bricolage, da decoração aos cuidados com animais, a possibilidade de propagação de marcas e produtos atingiu um desdobramento sem precedentes, reforçando a ideia de que a "televisão oferece a difusão de informações acessíveis a todos sem distinção de pertencimento social, classe social ou região geográfica. [...] A televisão dissemina a propaganda e orienta o consumo que inspira a formação de identidades" (HAMBURGUER, 2004: 440). Isso sem nos atermos aos canais de vendas que se posicionam de forma homóloga ao campo da publicidade e das produções televisivas, oferecendo produtos com demonstrações bastante ilustrativas (didáticas), com formas de pagamento e entrega facilitada aos mais longínquos recantos do país. Então, podemos concluir que nossos entrevistados, de forma geral, estão constantemente expostos a todas as mazelas comerciais oferecidas direta (canais de venda) ou indiretamente (novelas, programas culinários, de decoração etc.) pelas emissoras de televisão abertas ou por assinatura, constituindo um todo complexo, o universo simbólico de homologias que Bourdieu defende para caracterizar o campo.

A casa descrita pela maioria, é constituída espacialmente por sala, dois quartos, cozinha e banheiro, havendo, pequenas variações, como da casa de uma participe que por ser antiga é composta por duas salas. Temos também um exemplo com apenas um quarto. Quanto à localização, considerando o centro da cidade do Rio de Janeiro como referência, temos dois imóveis na região central (Rio Comprido e São Cristóvão), três na Zona Norte (Vila Isabel e dois no Andaraí), dois na região suburbana (Méier e Vaz Lobo) e um na Zona Oeste (Jacarepaguá). 
É importante dizer que o tamanho e a localização das residências revelou certa inquietação por parte de alguns entrevistados, como ocorrido em uma ocasião em que a entrevistada preocupou-se em deixar claro que o fato de morar de frente para a comunidade do Morro do Fogueteiro (conhecida por Favela Unidos de Santa Tereza) não trazia a ela nenhum demérito: "Não tenho vergonha em dizer que moro dentro de uma comunidade. [...] sou muito bem resolvida com relação a isso", mas a nosso ver, a sua insistência em frisar com conviç̧ão e aparente tranquilidade só reforça uma denegação da situação real em que se encontra com sua família.

Um exemplo contrário nesse aspecto foi de uma entrevistada, que na posição social de adquirente de um imóvel novo, transmitiu simbolicamente que a nova casa era um signo de distinção e que, além disso, mesmo antes de ocupá-la, vinha gradativamente preparando-a de forma que fosse possível alcançar a tão desejada qualificação clean que se traduz em um ambiente onde tudo está organizado, guardado, prático para ser localizado e utilizado a qualquer momento, ao mesmo tempo, devidamente camuflado, longe dos olhares curiosos e críticos dos visitantes. Verifica-se que limpeza, arrumação, praticidade representam uma forma de racionalização em que a casa é organizada como se fosse uma fábrica, volatilizando a outrora rígida fronteira entre o local de trabalho e o de moradia. A clássica estética do equilíbrio harmônico das diferentes partes, eventualmente evocativa da estética da antiguidade clássica, é a moderna busca por uma unidade na configuração das diferentes peças ou cores do mobiliário e a concretização de uma moral que antes chamaríamos de pequeno-burguesa, mas que poderia ser renomeada de ética da "classe batalhadora". O clean, que da mesma forma foi referenciado por outra entrevistada, também pode ser traduzido no uso de tons claros, superfícies mais lisas e com o mínimo de detalhes, além da redução de elementos (objetos) decorativos que componham o ambiente, reforçam a ideia de organização e enaltecem o conceito de limpeza e higiene, conforme identificou Forty (2008: 217).

O problema da sala pequena é recorrente, tendo sido citado de forma veemente em quatro ocasiões, nas quais ficou patente que a restrição de espaço funciona como limitador do conforto, exigindo por parte desses agentes atenção redobrada na aquisição de bens que já se constitui como um consumo regulado pelo gosto do necessário, conforme nos aponta Bourdieu (2008: 350), que se impõe mesmo que por um instante sejamos ludibriados por promoções ou produtos que já se encontrem ao alcance do capital econômico, como declarado em muitas das entrevistas. Assim sendo, nos atrevemos a afirmar que o espaço dos interiores residenciais nos moldes tradicionais, funciona como um terrível e constrangedor elemento de distinção social.

Mas não resta dúvida de que o que interessa realmente a todos esses batalhadores é ter um local de descanso, depois de um dia de trabalho, que ofereça um certo conforto com alguma apresentação. O que pode ser confirmado pela aflição sentida por uma participe na hora de voltar para casa: "Porque eu quero ir para minha casa, pra o meu sofá [...] quero ver minha novela, quero ver minha televisão, [...] Gosto de chegar na minha casa, dar graças a Deus de todo dia conseguir chegar em casa". Enfim, estar de acordo com aquilo que foi arbitrado socialmente para ser uma "casa", 
ou um espaço, ou territorialidade, que dá condição de possibilidade de existência de um móvel chamado sofá.

A palavra "aconchegante" manifestada com frequência, surge como um alento para reforçar a noção de lar digno de uma família. Na falta dela temos palavras carinhosas, expressas no diminutivo, verificadas em comentários como: "ter um espaçozinho bem agradável", ou "a minha casa é o meu mundozinho". Enfim, o que importa mesmo é ter um "canto", onde se possa descansar dignamente em paz com a família conforme uma participante declarou sobre sua casa: "está de bom tamanho e graças a Deus eu tenho onde morar".

No entanto, por menor que seja o espaço, existem elementos considerados básicos que "não podem faltar" no espaço da sala, o que pode ser confirmado pelas declarações de uma participante, quando recuperou sua mesa de jantar, que estava sendo usada pelo marido, além de substituir o colchão adaptado para assistir TV por um sofá novo de três lugares. Essa recomposição do espaço da sala, tranquilizou a entrevistada, primeiro, como exemplo para a formação de seus filhos, pois "as crianças não tinham uma referência de casa porque a gente não tem uma sala arrumada, não têm referência de casa", na verdade sua justa preocupação encontra sentido pela necessidade da formação do habitus primário que seus filhos levarão para suas vidas, conscientes ou inconscientes, da constituição física necessária para uma casa de família (PEREIRA e CATANI, 2002: 111). Segundo, pela eliminação do problema da ausência de lugares para acomodar os amigos que viessem visitá-la. Não é difícil notar que o bem receber traduz-se na noção do acomodar as pessoas realmente sentadas, de forma que elas se sintam confortáveis e bem acolhidas, pois o que está arbitrado é que as pessoas precisam se sentar, de preferência em um sofá, para se sentirem confortáveis.

Pelo que foi verificado a maioria das pessoas manifestou algum tipo de insatisfação com suas casas, como se estivesse faltando alguma coisa a ser providenciada. Nesse sentido, o pouco tempo disponível para tratar dessas pendências as aparentes limitações de capital cultural e, certamente, de capital econômico impedem a concretização dessas pretensões. Daí a disposição da entrevistada mais caseira, que por não recorrer, em suas horas de lazer, a saídas e badalações, direciona os recursos à sua casa, investindo em coisas consideradas básicas, evidenciando o fato de que nesse pequeno "mundozinho" tudo é feito dentro do possível, "nada muito caro. Móveis das Casas Bahia, mas tudo arrumadinho".

Como solução para possíveis angustias daí derivadas existem as estratégias que apesar de darem a impressão de que possam ser deduzidas diretamente das condições objetivas, uma vez que elas garantem uma economia de dinheiro, tempo e esforços, em todos os casos, pouco rentáveis, as práticas populares têm como princípio a escolha do necessário ("isso não é para nós"), no sentido do que é tecnicamente necessário, "prático" (ou em outras palavras, funcional), isto é necessário para se apresentar "como deve ser, sem mais nada", e, ao mesmo tempo, do que é imposto por uma necessidade econômica e social que condena as pessoas "simples" e "modestas" a gostos "simples" e "modestos" (BOURDIEU, 2008: 355). 
Mesmo considerando as adversidades de uma residência, sempre existe um cômodo que expressa a preferência de seus moradores em uma casa. Nessa percepção, a sala foi apontada como preferida pela maioria. Dentre eles, a moradora do imóvel com duas salas, sempre que possível, aproveita para reunir toda família. Por outro lado, as pessoas que ficaram divididas entre o quarto e a sala, o fizeram pela possibilidade de recolhimento integral e íntimo, o ápice do aconchego com todo conforto que seus vencimentos possam pagar. Contudo, independente da preferência, houve um profundo reconhecimento da importância da sala, por ser o primeiro ambiente que as pessoas de fora conhecem da casa, refletindo a ideia de como o dono(a) da casa realmente é. Na verdade "as tomadas de posição, objetiva e subjetivamente, estéticas - [como] a decoração de uma casa - [constitui uma oportunidade do agente] experimentar ou afirmar a posição ocupada no espaço social como lugar a assegurar ou distanciamento a manter" (BOURDIEU, 2008: 57). Em outras palavras, será grande a chance de identificar o habitus (de classe) desses agentes e, por conseguinte, as possibilidades de aproximação ou distanciamento social, pois não podemos esquecer que de uma forma geral os bens/produtos são usados socialmente servindo como cercas ou como pontes, conforme nos asseveram Douglas e Isherwood (2009: 36).

Para realizar a compra do sofá a preferência do grupo entrevistado ficou com o Rio Decor, que é um tipo de shopping de móveis que concentra dezenas de lojas do ramo, sendo frequentado por consumidores de diferentes níveis socioeconômicos. Identificamos que o aglomerado de estabelecimentos, a diversidade de modelos oferecidos e os preços praticados são atrativos que na verdade explicam a preferência de mais da metade dos entrevistados para compra do sofá. Tendo a importância desembolsada para compra do produto ficado na faixa entre $R \$ 800,00$ e $R \$ 1700,00$.

Não podemos deixar de reconhecer que um dos principais motivos para compra de um sofá novo é o desgaste que naturalmente vai ocorrendo com o estofado, principalmente com o revestimento, pelo uso intenso a que é submetido. No lugar de comprar um sofá novo, o problema poderia ser resolvido com a substituição da forração, mas o trabalho é considerado caro e, mesmo que estivesse barato, a pressão da moda pode exercer um forte sentimento de cansaço e até de enjoo em relação ao produto. Nesse caso percebemos esse comportamento pode ser um disfarce de um prazer que "vem sancionar psicologicamente imposições doutra ordem, imposições de diferenciação social e de prestígio. O efeito da moda só aparece nas sociedades de mobilidade social" (BAUDRILLARD, 1972: 69).

No entanto temos também soluções criativas impostas pela situação de orçamento limitado para sustentar financeiramente as trocas constantes que fez com que uma participe apelasse para o uso de uma capa que protege seu sofá da presença descuidada das crianças, distrai o sentimento de cansaço (ou enjoo), além de propiciar outras combinações no ambiente da sala, contribuindo para esticar um pouco mais a vida útil do produto.

Além do desgaste, existem outros motivos para a compra de um sofá novo, sendo o mais urgente e evidente, o fato da pessoa não ter o sofá. Observamos no entanto que, entre a necessidade da compra e sua efetivação, é comum existir um 
longo percurso. De acordo com os entrevistados é recomendável fazer uma busca na internet para se ter uma ideia dos modelos existentes e dos preços praticados, para depois ir às lojas, mais seguros do que procurar - na visão deles, a compra pode ser feita pela internet, mas nunca sem antes tocar, sentar, "sentir o sofá". Em todos os casos levantados a compra foi efetivada nas lojas físicas.

Obviamente que cada aquisição de sofá ocorreu em condições particulares, como o caso de uma promoção realmente vantajosa, pela qual uma de nossas partícipe foi atraída com o marido para compra de um rack. Na ocasião ela encontrou um sofá que embora não fosse do seu gosto, tinha atributos de conforto que associado ao preço promocional, além da possibilidade combinação da cor, que justificavam plenamente a compra. Essa situação vem ao encontro do objetivo dos vendedores, que se valem das promoções de venda para "conseguir suspender os freios e as censuras que impedem o desperdícios por meio da exibição dos consumos" (BOURDIEU, 2008: 356).

Em outro exemplo temos o caso da participante mais nova com seu jovem esposo que além da inexperiência, da falta de recursos e do problema do espaço reduzido da sala, certamente foram constrangidos pelo financiamento oferecido por seus pais para a compra do mobiliário, impedindo uma postura mais espontânea do casal. Mesmo considerando que ela tenha insistido, durante a entrevista, que tudo foi escolhido pelos dois, algumas ações demonstraram não ser bem assim. O próprio sofá de dois lugares por ela adquirido, só foi comprado por sugestão do vendedor, que conseguiu convencê-los. Contudo o casal acabou por escolher o revestimento em tecido suede em um tom claro, que tinha a intenção de combinar com o branco e o preto utilizado nos outros elementos presentes na sua sala.

Em outra passagem, temos a urgência da entrevistada, que intencionava primeiro transmitir aos filhos a ideia de uma verdadeira sala de um lar, para depois ter uma sala em condições de receber seus amigos, o que levou ela e o marido a escolherem um sofá de três lugares com sistema retrátil e encosto reclinável. $\mathrm{Na}$ opinião dos dois, o sofá pode até não ser o mais bonito, mas é muito confortável. 0 revestimento escolhido por ela foi o suede em tom de verde, sem medo de errar, pois mesmo que tivesse ocorrido algum deslize nessa escolha, ela deixou claro que, tendo condições, trocaria o sofá de três em três anos!

A situação da moradora do Rio Comprido para efetivação da compra do sofá foi mais delicada em virtude da forte limitação em capital econômico e do pouco tempo disponível para levantar informações sobre o assunto que permitiria ao casal tomar a decisão certa sem erros. O sofá escolhido foi um de três lugares revestido em tecido suede verde escuro, que ao mesmo tempo que é "fofinho" e aconchegante, suportará as travessuras de sua filha pequena bem como o relaxamento despreocupado de seu filho adolescente. Ela também providenciou uma capa para proteger o sofá e ao mesmo tempo combinar com a cortina da sala. Novamente, faz-se presente 0 consumo (e o gosto) de necessidade, além de uma imposição de ordem econômica, que se perdurar condenará a família a ficar cada vez mais distante dos lançamentos da moda. 
A compra do sofá da entrevistada de São Cristóvão ocorreu respeitando o padrão normal de comportamento das classes populares, envolvendo levantamento e comparação de modelos, acabamentos e preços. Ela declarou que identificou o modelo do sofá logo assim que o viu: com assento retrátil, encosto reclinável e o revestimento suede na cor "cinza médio". Muito embora a escolha tenha sido feita em comum acordo com o marido, houve uma pequena desavença gerada pelo fato dele preferir o modelo tipo bicama, o que na opinião da partícipe seria um absurdo pois a sala pareceria com um quarto de hóspedes, gerando, a nosso ver, uma distorção simbólica.

A justificativa da escolha do tecido na cor "cinza médio" veio em função da combinação com a parede que será pintada em uma cor grená, por sugestão da amiga que entende de decoração. Além disso, esse cinza esconde a sujeira e deve resistir um pouco mais às brincadeiras de seu filho, do que o tom de cinza mais claro que ela prefere. Novamente temos a demonstração de um consumo definido pela necessidade e urgência, na qual os fatores funcionais é que falam mais alto. Inclusive o próprio modelo de sofá parece não ser exatamente o que ela queria, pois sua ideia era ter um sofá-cama para acomodar as visitas, mas o preço e o tamanho do modelo inviabilizaram a escolha. Mesmo assim, a influência de sua amiga e dos sites de tinta nas descrições das combinações e soluções espaciais, acusam uma familiaridade com a cultura da decoração no aproveitamento de espaços que ocorre com certa frequência à pequena burguesia, desenvolve prodígios de energia e engenhosidade para viver, como se diz, "acima de seus meios" por exemplo, na ordem da habitação, o artifício dos "cantos" [...] destinados a multiplicar os cômodos ou os "truques" apropriados para ampliá-los, "áreas de arrumação", [...] "sofás-camas", sem falar de todas as formas de símile e de todas as coisas capazes de "fazer", [...], algo diferente do que elas são, ou seja, outras tantas maneiras utilizadas pelo pequeno para "tornar grande"(BOURDIEU, 2008: 300).

O exemplo mais destoante observado diz respeito a entrevistada do Andaraí que guardava uma condição limitada em capital econômico e cultural, associada a uma forte restrição espacial de sua sala de visitas. Para realizar a compra do estofado com uma certa urgência, ela preferiu buscar opções diretamente nas lojas físicas. Tendo encontrado um modelo exposto na loja do Ponto Frio, usando como critério de escolha o comprimento, assento e encosto que impedissem o "deitar" e o revestimento, que resistisse a luz do sol que incide em sua sala. Isso posto, podemos dizer que o sofá adquirido é um modelo de três lugares com um tecido escuro (não identificado), com o conjunto assento e encosto que só permite a postura sentada. Dessa forma ela atingiu seus objetivos de liberar a passagem e acomodar as pessoas no sofá para uma conversa mais tranquila, dispensando o "conforto" que a grande maioria dos nossos entrevistados procuravam: o relaxar, o deitar, o cochilar de preferência diante da televisão - tudo o que ela não queria. É oportuno ressaltar que embora ela tenha demonstrado indiferença quanto às características visuais do sofá, o tecido escuro parece ter sido escolhido com base no modelo na cor preta comprado pelo vizinho, que, segundo ela tem um bom gosto e só compra coisa boa. Ou seja, ela se baseou em uma referência de uma fração dominante da sua vizinhança. 
No caso da moradora do Méier, ela já tinha uma ideia do que queria, não sendo difícil de chegar ao modelo no formato em "L", com três lugares, sendo que em uma das extremidades o assento é prolongado para que seja possível ficar deitado. Quanto ao revestimento, ela escolheu o suede na cor "beterraba, puxando pro vinho", que resiste à poeira, sem ser um preto que, pelo que entendemos, pode fechar o ambiente. A exemplo da outra entrevistada citada acima, ela também tende a se cansar das coisas, recorrendo a constantes alterações da posição dos móveis de sua sala. No nosso entender, essa associação é uma forma de deixar manifestado no ambiente sempre transformado a impressão de sua personalidade, conforme nos assevera Forty com base no trabalho de Elsie de Wolfe (FORTY, 2007: 145). Assim sendo, não poderia deixar de ser diferente sua manifestação já prevendo a substituição do sofá num futuro próximo, pela impossibilidade de colocá-lo em outra posição que não seja a atual, obstruindo sua expressão pessoal.

\section{CONSIDERAÇÕES FINAIS}

Pelo que foi levantado, as entrevistas realizadas confirmaram a presença de violência simbólica oriunda dos processos de inculcação, que, associada ao arbitrário social de como a sala de uma casa deve ser, seus elementos básicos e possíveis combinações, exercem forte pressão sobre esses agentes pela aquisição do sofá, com uma certa orientação de configuração e tipo de revestimento que os próprios fabricantes cuidam de oferecer no mercado, estofados com diferenças tão sutis (que pode ser confirmado nas lojas do Rio Decor), que tivemos a oportunidade de agrupálos por suas características estético formais orientadas pelo que chamamos de modelo hegemônico de sofá.

\section{REFERÊNCIAS}

BAUDRILLARD, Jean. A moral dos objetos. In: Semiologia dos objetos. Petrópolis: Vozes, 1972.

BEAUD, S. \& WEBER, F. Guia para pesquisa de Campo. Produzir e analisar dados etnográficos. Petrópolis: Vozes, 2003.

BOURDIEU, Pierre. A Distinção: crítica social do julgamento. São Paulo: EDUSP; Porto Alegre: Zouk, 2008.

. Questões de Sociologia. Lisboa: Fim de Século Edições, 1984.

DOUGLAS, Mary e ISHERWOOD, Baron. 0 mundo dos bens. Para uma antropologia do consumo. Rio de Janeiro: UFRJ, 2004.

FORTY, Adrian. Objetos de Desejo. São Paulo: Cosac Naify, 2008.

FREYRE, Gilberto (1977). Ingleses no Brasil. Rio de Janeiro: José Olympio Editora, 1977.

HAMBURGUER, Esther. Diluindo Fronteiras: A televisão e as novelas no cotidiano. In: História da Vida Privada no Brasil: Contrastes da intimidade contemporânea. Org. Lilia Moritz Schwarcz. São Paulo: Companhia das Letras, 1998. Vol. 4. 
LIMA, Marco Antonio Magalhães. O consumo estético-simbólico do sofá. 2015. $224 f$. Tese. Rio de Janeiro: Pontifícia Universidade Católica do Rio de Janeiro, Programa de Pós-Graduação em Design 2015.

MARCONI, Marina de Andrade; LAKATOS, Eva Maria. Metodologia Científica. São Paulo: Atlas, 1991.

PEREIRA, G. R. de M. e CATANI, A. M. Espaço social e espaço simbólico: introdução a uma topologia social. Perspectiva. Florianópolis,v. 20, n. Especial, p. 107-120, jul./dez.2002.

RYBCZYNSKI, Witold. Casa - Pequena História de uma ideia. Rio de Janeiro: Record, 1999.

DeAgostini, c1999. 1 CD-ROM. 